\title{
Modelling of channel transmission loss processes in semi-arid catchments of southern Africa using the Pitman Model
}

\author{
Vuyelwa Mvandaba ${ }^{1,2}$, Denis Hughes ${ }^{2}$, Evison Kapangaziwiri ${ }^{1}$, Jean-Marc Mwenge Kahinda ${ }^{1}$, and \\ Nadia Oosthuizen ${ }^{1,2}$ \\ ${ }^{1}$ CSIR, Natural Resources and Environment, P.O. Box 395, Pretoria, 0001, South Africa \\ ${ }^{2}$ Institute for Water Research, Rhodes University, P Bag 94, Grahamstown, 6140, South Africa
}

Correspondence: Vuyelwa Mvandaba (mvandabav@gmail.com)

Received: 12 November 2017 - Revised: 24 January 2018 - Accepted: 31 January 2018 - Published: 29 May 2018

\begin{abstract}
Water availability is one of the major societal issues facing the world. The ability to understand and quantify the impact of key hydrological processes, on the availability of water resources, is therefore integral to ensuring equitable and sustainable resource management. Channel transmission losses are an "under-researched" hydrological process that affects resource availability in many semi-arid regions such as the Limpopo River Basin in southern Africa, where the loss processes amount to approximately $30 \%$ of the water balance. To improve the understanding of these loss processes and test the capability of modelling routines, three approaches using the Pitman model are applied to selected alluvial aquifer environments. The three approaches are an explicit transmission loss function, the use of a wetland function to represent channel-floodplain storage exchanges and the use of a "dummy" reservoir to represent floodplain storage and evapotranspiration losses. Results indicate that all three approaches are able to simulate channel transmission losses with differing impacts on the regional flows. A determination of which method best represents the channel transmission losses process requires further testing in a study area that has reliable observed historical records.
\end{abstract}

\section{Introduction}

Channel transmission losses describe surface water and groundwater interactions where streamflow is reduced by evaporation from free water surfaces, evapotranspiration from the recharged river bed and banks, infiltration into channel beds, banks and flood plains and evapotranspiration from riparian vegetation (Smakhtin and Watkins, 1997). Compared to other hydrological processes, information on channel transmission losses remains largely lacking, however the dynamics between alluvial aquifers (alluvium) and channel transmission losses have been covered by several hydrological studies across the world (Boroto and Görgens, 2003; Lange, 2005; Costa et al., 2012; Jarihani et al., 2015). From these studies it is understood that, due to their water storage capabilities, the presence of alluvial aquifers results in significant channel transmission losses in ephemeral river systems found in semi-arid catchments such as the Limpopo River
Basin of southern Africa (Boroto and Görgens, 2003). Ultimately, channel transmission loss processes affect the availability of streamflow, hence it is imperative to understand their role in the alluvial aquifers of the Limpopo River Basin.

\section{The Pitman Model}

The Pitman Model (Hughes, 2004) is a conceptual, monthly time-step and spatially semi-distributed rainfall-runoff simulation model. Its main application, as one of the most extensively used models within southern Africa (Tshimanga et al., 2011), has been as a water resource estimation tool for basinwide water resource assessments and planning (Kapangaziwiri et al., 2011). Revisions to the model have included incorporation of groundwater recharge and discharge functions as well as the addition of an explicit transmission loss function (Hughes et al., 2013) designed to account for riparian evapotranspiration losses and losses from storage due to sub- 
(a)

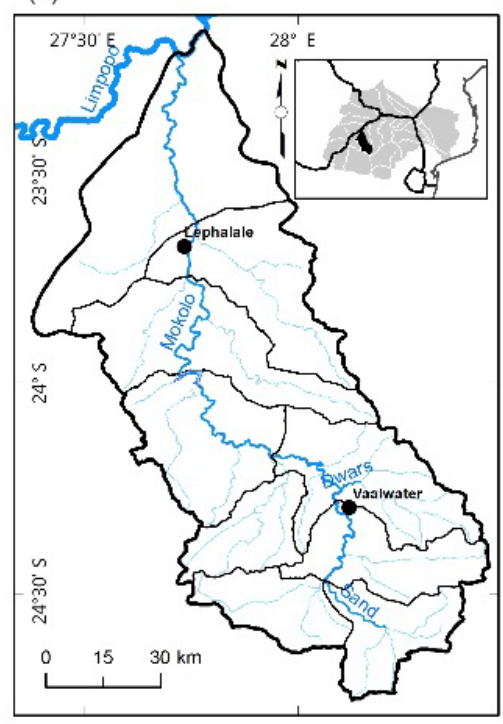

(b)

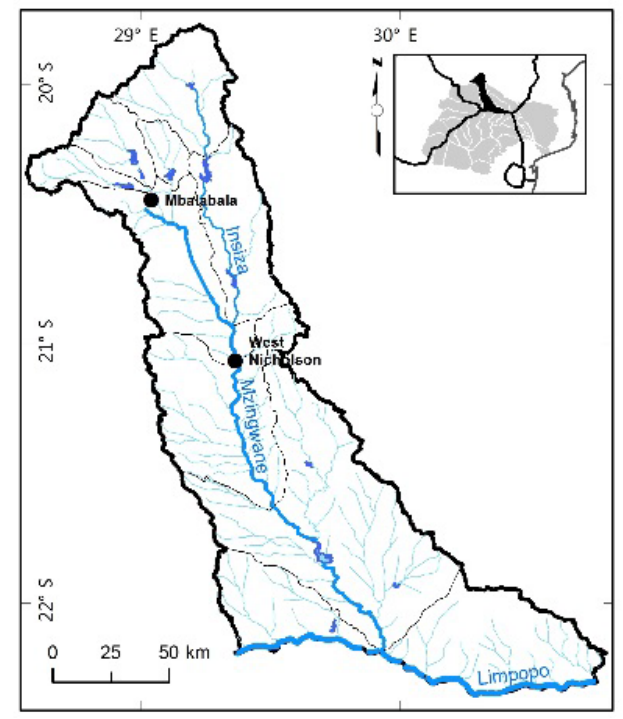

Figure 1. Map of the Mokolo (a) and Mzingwane (b) sub-basins and their locations in the Limpopo River Basin.

surface outflow to downstream areas. Prior to the development of the transmission loss function, streamflow losses to adjacent alluvial aquifers were simulated using a wetland function to represent channel-floodplain storage exchanges and a "dummy" reservoir to represent floodplain storage and evapotranspiration losses.

\subsection{The transmission loss function}

The transmission loss function relies on a simple geometry which conceptualises the water balance within the groundwater store. The process of simulating transmission losses in the model assumes that the rate of loss will be due to characteristics of the channel, the head difference between the channel and the groundwater and the transmissivity of the material under the channel (Hughes et al., 2007). The function simulates two groundwater gradients which, when negative, relate the loss of water from channel to aquifer.

\subsection{The wetland function}

The wetland function is based on a simple water balance approach with water draining into and out of the wetland. The function was added to the model to account for the downstream impact of wetlands and natural lake systems on streamflow (Hughes et al., 2013). Processes associated with wetlands and lakes can exert a considerable influence on downstream flow regimes through attenuation, storage and slow release processes that occur within the water bodies. These processes are critical in understanding the general patterns of runoff generation at the basin scale (Tanner, 2013).

\subsection{The reservoir function}

The basis of the reservoir function, as a water use component of the Pitman Model, is to simulate the impact of large dams on the basin's streamflow. A study (Hughes et al., 2006) focussing on the impact of climate change and development scenarios on flow patterns in the Okavango River represented channel transmission losses as "dummy" reservoirs based on a quantification of channel lengths and widths of floodplains and swamps - riparian areas that were hypothesised to be fed by seepage from the river, and from which water was assumed to evaporate, were modelled as open water surfaces ("dummy" reservoirs). The study noted that the presence of the "dummy" reservoir reduced streamflow from the Omatako sub-basin to zero flow at the outlet, which is the right behavioural effect however not quite representative as parameter values used were based on inadequate information.

Detailed descriptions of each function are provided by Hughes (2004), Hughes et al. (2007), Kapangaziwiri (2008) and Tanner (2013).

\section{Study areas}

Two sub-basins of the Limpopo River Basin were selected as study areas, namely the Mokolo (South Africa) and the Mzingwane (Zimbabwe) (Fig. 1).

\subsection{The Mokolo sub-basin}

The Mokolo sub-basin $\left(8417 \mathrm{~km}^{2}\right)$ falls within the South African portion of the Limpopo and comprises 9 catchments, namely A42A to A42J. The sub-basin is characterised by an 


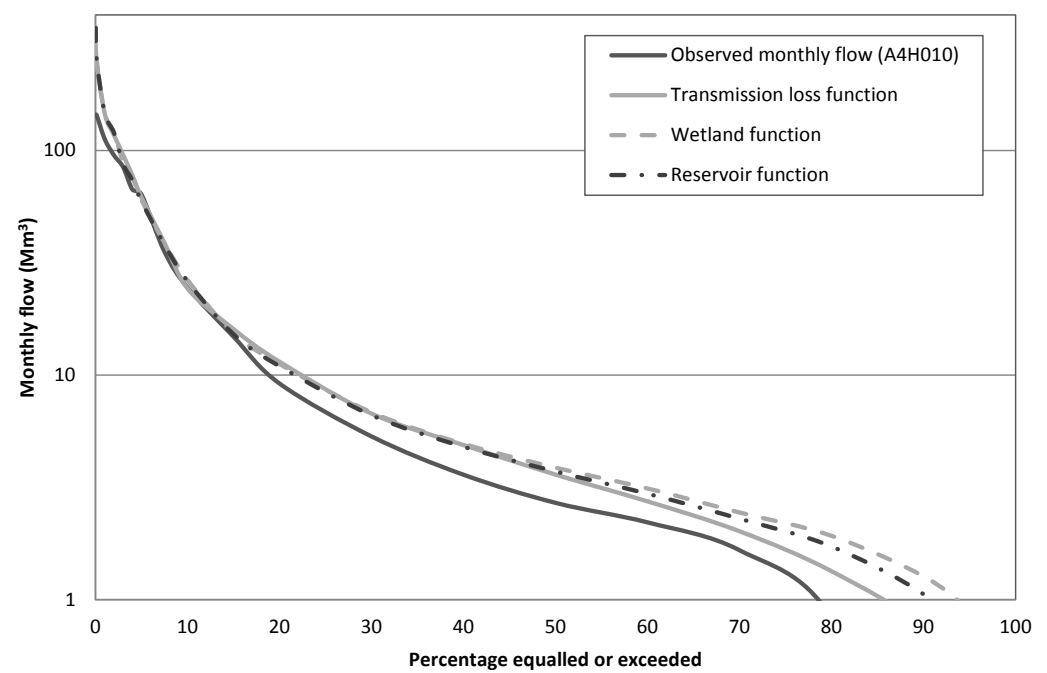

Figure 2. Comparison of flow volumes $\left(\mathrm{Mm}^{3}\right)$ at selected flow duration curve percentage points for the Mokolo sub-basin.

arid to semi-arid climate (DWA, 2014) with mean annual precipitation (MAP) and evaporation (MAE) of 350 to 700 and $1900 \mathrm{~mm} \mathrm{a}^{-1}$, respectively. The flow of the Mokolo River and its tributaries is highly regulated and largely perennial, except for the lower reaches and other lower order streams, which respectively display ephemeral (summer flow) and episodic characteristics (Boroto and Görgens, 1999). The hydrogeology of the Mokolo sub-basin comprises fractured and intergranular secondary aquifers as well as quaternary alluvium which constitute primary alluvial aquifers along the riverbed of the river Mokolo and some of its tributaries (Titus and Rossouw, 2008). Water use in the sub-basin is dominated by agriculture, industrial use, mining and domestic use (DWA, 2012).

\subsection{The Mzingwane sub-basin}

The Mzingwane sub-basin is situated in the Zimbabwe portion of the Limpopo River Basin (Howard et al., 2013). A semi-arid climate dominates the sub-basin with areas in the upper reaches of the sub-basin receiving a MAP of 300 to $800 \mathrm{~mm} \mathrm{a}^{-1}$ (Love et al., 2007) and MAE of more than $1800 \mathrm{~mm} \mathrm{a}^{-1}$ (Howard et al., 2013). The ephemeral Mzingwane River is highly developed. Aquifers in the Mzingwane sub-basin comprise both secondary fractured and primary alluvial aquifers (CSIR, 2003). Major water uses in the subbasin are for domestic, industrial, mining and agricultural purposes (Mabiza et al., 2007).

\section{Model set up and channel transmission loss modelling approach}

The Pitman model was set up for both the Mokolo and Mzingwane sub-basins, using the Spatial Time Series Information Modeling (SPATSIM) software (Hughes and Forsyth,
2006). Model inputs for each catchment of the Mokolo sub-basin were based on the regional information available in the Water Resources of South Africa 2005 (WR2005) study (Middleton and Bailey, 2009). Monthly flow volume recorded at gauge A4H010, which is located near the outlet of A42F, was used for validation of the transmission loss simulations given that the flow gauge station at the outlet of the Mokolo River was found to have insufficient data. The data was accessed from the South African Department of Water and Sanitation Hydrological Information System and covers the time period 1979 to 2017. A series of eights nodes, depicting flow gauge stations was used for the setup of the Mzingwane sub-basin. The flow gauges represented include B20, B60, B75, B22, B62, B91, B90 and BUZMZ. Parameter inputs, based on data implemented in the updated Blue Book (Mazvimavi, 2006) and the recent Limpopo River Basin Monograph Study (Howard et al., 2013), were used to populate each of the nodes. Flow gauge B20, which is the most upstream station in the setup, was used for reporting as gauges further downstream were found to be highly impacted by irrigation dams found along the Mzingwane River.

To compare the three transmission loss simulation approaches, each function was ran independently and then the simulation outputs were used to assess the degree of change between the observed flow (no transmission losses included) and a model run with channel transmission losses. Additionally, the outputs simulated by the transmission loss function, wetland function and "dummy" dam function were also compared to determine which function performed better in simulating the estimated channel transmission losses for each sub-basin. The alluvial aquifer storage in each sub-basin and hence the potential quantity of channel transmission losses was calculated by using the dimensions of alluvial aquifers delineated in each sub-basin. 


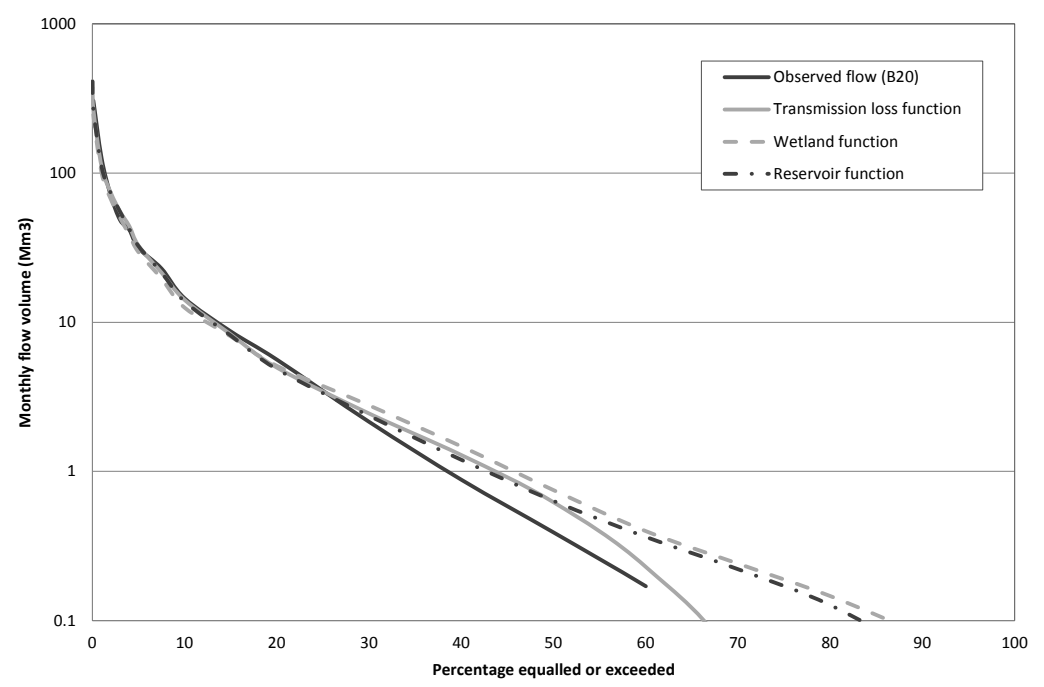

Figure 3. Comparison of observed and simulated flow $\left(\mathrm{Mm}^{3}\right)$ for the Mzingwane sub-basin.

\section{Results and Discussion}

An assessment of the model performance was carried out, after the inclusion of channel transmission losses based on an evaluation of the correlation between observed and simulated flow, based on the recommended statistics for model performance by Moriasi et al., 2007. The model performances for both the Mokolo and Mzingwane sub-basins were satisfactory $(\mathrm{CE}>0.50$, PBIAS $<25)$ even before the inclusion of channel transmission losses, however the simulated mean monthly flows were significantly greater than the observed flow. The results of the channel transmission loss simulations are presented on a flow duration curve (FDC) which illustrates the correlation between the simulated monthly flow volume and the observed monthly flow volume.

Channel transmission losses measuring $55 \mathrm{Mm}^{3}$ were estimated for catchment A42F, based on results acquired from delineation and characterisation of alluvial aquifers in the Mokolo sub-basin. The transmission loss, wetland and reservoir functions respectively simulated channel losses measuring $2.2 \mathrm{Mm}^{3}$ month $^{-1}\left(26.4 \mathrm{Mm}^{3} \mathrm{a}^{-1}\right), 56.95 \mathrm{Mm}^{3}$ and $54.78 \mathrm{Mm}^{3}$. Following the inclusion of transmission losses, simulated MAR measuring $11.71 \mathrm{Mm}^{3}$ was respectively reduced to $11.47 \mathrm{Mm}^{3}$ and $11.60 \mathrm{Mm}^{3}$ by the transmission loss and reservoir functions; MAR increased to $11.72 \mathrm{Mm}^{3}$ when losses were added through the wetland function. Observed flow from gauge A4H010 was however over-simulated particularly along the middle and low flows (Fig. 2) because of unaccounted water uses, due to lack of data.

For the Mzingwane sub-basin, channel transmission losses measuring $5 \mathrm{Mm}^{3}$ were estimated for node B20. The transmission loss, wetland and reservoir functions respectively simulated channel losses measuring $0.39 \mathrm{Mm}^{3}$ month $^{-1}$ $\left(4.68 \mathrm{Mm}^{3} \mathrm{a}^{-1}\right), 4.93 \mathrm{Mm}^{3}$ and $4.97 \mathrm{Mm}^{3}$. Following the inclusion of transmission losses, simulated MAR measuring
$6.539 \mathrm{Mm}^{3}$ was respectively reduced to $6.486,6.141$ and $6.471 \mathrm{Mm}^{3}$ by the transmission loss, wetland and reservoir functions. On the flow duration curve, which is presented on a logarithmic graph (Fig. 3), it is evident that the simulated high flows compare relatively well to the observed high flows however both medium and low flows are over-simulated. Similar to the Mokolo sub-basin, the over-simulation of flow is associated with inadequate representation of water use impacts in the sub-basin. This over-simulation is further evidenced by the relative steepness of the flow duration curve which indicates that high flows are being simulated at a greater frequency than expected.

\section{Conclusion}

Channel transmission losses play a significant role in the water balance of the Limpopo River Basin, therefore understanding the dynamics which influence loss processes and quantifying the impact on water resources is integral for advancing knowledge and improving water resource management. The aim of simulating channel transmission losses with three different functions of the Pitman Model was to assess the capability of existing loss modelling routines and determine which of the three functions best represents the dynamics of channel transmission losses processes. Transmission loss simulations were conducted in the Mokolo and Mzingwane sub-basins of the Limpopo River Basin and results indicate that all three functions were able to simulate losses, although with differing magnitudes. Observed monthly flow data was used to as a means of validating loss simulations however in both examples, medium and low flows were oversimulated which accounts for water uses that were inefficiently represented due to lack of data. Knowledge of the structure of the transmission loss function dictates that it is 
better at representing the dynamics of channel transmission losses, as it takes into account the contribution of losses to groundwater recharge whereas the other two functions do not.

Overall, the results from the two modelling examples demonstrate the potential of each approach in reproducing the dynamics of channel transmission losses between channel and alluvial aquifer within an existing sub-basin scale hydrological model. It is believed that better quantification of losses and more efficient qualitative determination of the function which best represents transmission losses, can be attained with more reliable observed data.

Data availability. Data not publicly available as they were obtained from a consultant with the caveat that they would only be used for the project and not shared publicly. However, the data will soon be available on LIMIS which is managed by the Limpopo River Basin Commission who contracted the consultant to collect the data.

Competing interests. The authors declare that they have no conflict of interest.

Special issue statement. This article is part of the special issue "Understanding spatio-temporal variability of water resources and the implications for IWRM in semi-arid eastern and southern Africa". It is a result of the IAHS Scientific Assembly 2017, Port Elizabeth, South Africa, 10-14 July 2017.

Acknowledgements. This paper forms part of a project titled: "Upstream-Downstream Hydrological Linkages in the Limpopo River Basin" which is co-funded by the Water Research Commission, Pretoria, South Africa (Project K5/2439/1) and the CSIR parliamentary grant (ECHS052).

Edited by: Hodson Makurira

Reviewed by: Cosmo Ngongondo and one anonymous referee

\section{References}

Boroto, R. A. J. and Görgens, A. H. M.: Hydrological Modelling of the Limpopo River Main Stem, report by: Department of Civil Engineering, University of Stellenbosch and Ninham Shand Consulting Engineers, Department of Water Affairs \& Forestry, DWAF Report No. PA000/00/0399, 105 pp., 1999.

Boroto, R. J. and Görgens, A. H. M.: Estimating transmission losses along the Limpopo River: an overview of alternative methods, International Association of Hydrological Sciences Publication, 278, 138-143, 2003.

Costa, A. C., Bronstert, A., and de Araújo, J. C.: A channel transmission losses model for different dryland rivers, Hydrol. Earth Syst. Sci., 16, 1111-1135, https://doi.org/10.5194/hess-16-11112012, 2012.
CSIR (Council for Scientific and Industrial ResearchEnvironmentek): Protection and strategic uses of groundwater resources in drought prone areas of the SADC Region: Groundwater situation analysis of the Limpopo River Basin Final Report, Environmentek Report No. ENV-P-C 2003-026, Pretoria, 2003.

DWA (Department of Water Affairs): Classification of Significant Water Resources in the Mokolo Catchment: Limpopo Water Management Area (WMA) and Crocodile (West) and Marico WMA WP 10506: Information Analysis Report: Mokolo and Matlabas catchments: Limpopo WMA, Report No: RDM/WMA1,3/00/CON/CLA/0112B, Pretoria, South Africa, 2012.

DWA (Department of Water Affairs): Classification of significant water resources in the Crocodile (West), Marico, Mokolo and Matlabas catchment: Management Classes Report, Report No: RDM/WMA1, 3/00/CON/CLA/0612, Pretoria, South Africa, 2014.

Howard, G., Denys, F., Walker, N., and Görgens, A.: Volume C1 Surface Water Hydrology: Limpopo River BasinMS-81137945, Supplementary Report to Final Limpopo River Basin Monograph, prepared for LIMCOM, 2013.

Hughes, D. A. and Forsyth, D. A.: A generic database and spatial interface for the application of hydrological and water resource models, Comput. Geosci., 32, 1389-1402, 2006.

Hughes, D., Andersson, L., Wilk, J., and Savenije, H. H. G.: Regional calibration of the Pitman model for the Okavango River, J. Hydrol., 331, 30-42, 2006.

Hughes, D., Parsons, R., and Conrad, J.: Quantification of the Groundwater Contribution to Baseflow, WRC Report No. 1498/1/07, Water Research Commission, Pretoria, South Africa, 2007.

Hughes, D. A.: Incorporating ground water recharge and discharge functions into an existing monthly rainfall-runoff model, Hydrolog. Sci. J., 49, 297-311, 2004.

Hughes, D. A., Tshimanga, R. M., Tirivarombo, S., and Tanner, J.: Simulating wetland impacts on stream flow in southern Africa using a monthly hydrological model, Hydrol. Process., 28, 17751786, 2013.

Jarihani, A. A., Larsen, J. R., Callow, J. N., McVicar, T. R., and Johansen, K.: Where does all the water go? Partitioning water transmission losses in a data-sparse, multi-channel and low-gradient dryland river system using modelling and remote sensing, J. Hydrol., 529, 1511-1529, 2015.

Kapangaziwiri, E.: Revised parameter estimation methods for the Pitman monthly rainfall-runoff model. MSc Dissertation, Rhodes University, Grahamstown, South Africa, 2008.

Kapangaziwiri, E., Hughes, D. A., Tanner, J. L., and Slaughter, A.: Resolving uncertainties in the source of low flows in South African rivers using conceptual and modelling studies. Conceptual and modelling studies of integrated groundwater, surface water and ecological systems, Proceedings of Symposium H01 held during IUGG 2011, Melbourne, Australia, July 2011, IAHS Publication, 345, 127-132, 2011.

Lange, J.: Dynamics of transmission losses in a large arid stream channel, J. Hydrol., 306, 112-126, 2005.

Love, D., Owen, R., Uhlenbrook, S., van der Zaag, P., and Moyce, W.: The lower Mzingwane alluvial aquifer: managed releases, 
groundwater-surface water interactions and the challenge of salinity, Interim Paper for WaterNet, 2007.

Mazvimavi, D.: Assessment of Surface Water Resources of Zimbabwe and Guidelines for Planning, Zimbabwe National Water Authority, 2006.

Mabiza, C. C., Van der Zaag, P., Manzungu, E., and Ahlers, R.: The making of a catchment plan: experiences of the Mzingwane Catchemnt, Zimbabwe, available at: http://hdl.handle.net/10568/ 21290 (last access: 1 April 2017), 2007.

Middleton, B. J. and Bailey, A. K.: Water Resources of South Africa, 2005 study, Water Research Commission Report Number TT 380/08, Water Research Commission, Pretoria, South Africa, 2009.
Smakhtin, V. Y. and Watkins, D. A.: Low-flow Estimation in South Africa, WRC Report 494/1/97, Pretoria, South Africa, 1997.

Tanner, J. L.: Understanding and Modelling of Surface and Groundwater Interactions, $\mathrm{PhD}$ Dissertation, Rhodes University, Grahamstown, South Africa, 2013.

Titus, R. and Rossouw, T.: Groundwater Reserve DeterminationStudy for Mokolo (A42) Catchment, Water Geosciences Consulting, Pretoria, South Africa, 2008.

Tshimanga, R. M., Hughes, D. A., and Kapangaziwiri, E.: Initial calibration of a semi-distributed rainfall runoff model for the Congo River basin, Phys. Chem. Earth, 36, 761-774, 2011. 